Session 2213

\title{
Integration of a Manufacturing Experience into the Undergraduate Curriculum in Polymer Engineering
}

\author{
Robert M. Briber, David I. Bigio / James Lochary \\ University of Maryland at College Park/ Adell Plastics, Inc.
}

\begin{abstract}
$\underline{\text { Abstract }}$
A new course titled "Manufacturing with Polymers" has been developed in the Engineering School at the University of Maryland which utilizes local industry as a resource for education by tightly integrating the normal classroom experience with manufacturing at local industrial facilities using production scale equipment. This course, as developed over the last two semesters by a cross disciplinary group of faculty from the Mechanical, Chemical and Materials Engineering Departments, involves developing, in collaboration with local industrial partners, a specific problem in polymer manufacturing which can be handled in a single semester by upper-level undergraduates working in teams of 2-4 students. The goal of the course is to provide students with a manufacturing experience outside of the normal University environment and to introduce the concepts of polymer engineering using the techniques of anchor teaching and just-in-time learning in response to needs identified by both the instructor and the students. The course draws on advanced topics (often first treated at the graduate level) which include non-Newtonian fluid dynamics, polymer processing, laminar mixing theory, polymer characterization, polymer blends, etc. The topics are introduced in logical order as they are needed for the project and as they are brought up by the students in response to their needs for making progress on the project.
\end{abstract}

The course combines work in the classroom, at the industrial manufacturing site and in oncampus laboratories. The classroom time is spent developing the basic background needed to communicate on the topics, anchor teaching of key concepts, formulating the project and presentations by guest lecturers (largely from industry).

\section{Introduction}

One of the most common complaints heard from engineering students, particularly at the upperclass level, is that they feel that too many of their courses are focused on the theoretical aspects of engineering and that they do not gain enough "hands-on" engineering experience during their time at the University to be competitive in the job market. It is clear that most universities do not have the resources to set up large scale manufacturing labs on campus for each of the engineering departments. Nevertheless, it is important to provide students with exposure to a manufacturing environment in an educational atmosphere during their course of studies. Schon describes the dilemma as one of rigor vs. relevance. What can be solved rigorously may have no practical relevance; whereas, industrial solutions rarely lead to any fundamental understanding ${ }^{1}$. Schon goes on to suggest an epistemology of "knowingin-action," or "tacit knowledge," should be the new form of scholarship.

To implement this type of learning experience at the University of Maryland, we enlisted the aid of local industry for help by opening up their manufacturing site for student projects. The polymer manufacturing/processing industry is a logical candidate for this type of University-Industry collaboration, as it is common to have various small polymer processing companies 
extrusion, compounding and injection molding even in areas of only little or no heavy industry (as often is true in University locations). The requirement is to contact local industries and propose that students, working in groups of 3 or 4, take on a project of mutual interest to the faculty, students and company as a semester project.

\section{Course Implementation}

\section{Course Structure}

We have implemented a course based on the model described above titled "Manufacturing with Polymers" at the University of Maryland for the past few semesters. The course is cross-listed in the Materials, Mechanical and Chemical Engineering Departments and draws students from each of these majors. We have been working with Adell Plastics, a plastics compounding company outside of Baltimore, Maryland to provide the students with the industrial production experience. Typically the class size has run about 10-12 students per semester. A questionnaire is distributed and collected from the students on the first day of class which asks for information on:

-Previous courses/experience with polymers. We have found that for many (50\% or greater) of the students, this is the first and probably only course in polymers they will take during their undergraduate degree.

- Whether the student has a car. The projects require travel to off-caroms sites and at least one car per student group is very helpful.

- The student's major. The members of a group should not all have the same major.

On the second day of classes we break the class into groups of 3-4 students using the questionnaires as the basis of forming the groups. The main criteria used in setting up the groups are that each group has a car and each group contains different majors. We have found that it is better to assign students to groups rather than letting them pick their own groups for a couple of reasons. First, if given a choice, the students are likely to choose group members from their same field of study and second, by putting students together in groups where they may not know everyone, you provide them with experience in working in teams which is similar to what they will experience after they leave the University. This aids in development of the philosophy of "total engineering development" for the students which includes: team building, project management, presentation skills, industrial-customer interactions, etc.

\section{Course Project}

It is important to identify the goals for the project early in the course, preferably within the first week of the semester. For example in the fall semester 1995 we worked with Adell Plastics, Inc. to design a new polymer formulation based on blending nylon 6 with polypropylene (PP) to attempt to gain many of the mechanical properties of nylon 6 (which has a relatively high modulus) for a cost similar to polypropylene (which is about half the price of nylon 6). By including the goals of both engineering properties and economics, the students gain experience in engineering design in the marketplace, where the product with the best set specifications does not always succeed due to economic constraints.

The specific implementation of the project is purposely left somewhat open to encourage the students to formulate the details of what they will be working on during the semester. To aid in this step a series of guest lecturers are brought in to help visualize the different issues which will need to be addressed by the student groups. 
Each group is asked to make a presentation in class on what is required to complete the project successfully. After the presentations the class assembles the ideas presented to formulate an overall plan of action. At this stage it becomes apparent that the project may be too large for a single group to complete all aspects and the project is generally divided up in to sub tasks which are assigned to different groups.

In the sample given above the steps identified in the project included:

- Identify the composition range of the polymer blend to be studied (i.e. nylon 6 / PP ratio)?

- Identify the appropriate screw design and the operating conditions for the extruder where the materials would be blended. This information would need to be transferred to the industrial sponsor for approval.

- Identify the techniques which will be used to characterize the final product and set goals for the product specifications. The characterization techniques included injection molding to form test specimens and evaluation of the mechanical properties and morphology by scanning electron microscopy (SEM).

The tasks were then divided up between the groups as follows:

- The entire class would be responsible for determining the appropriate extruder screw design and operating conditions. These would be communicated in writing to Adell Plastics, Inc. with enough lead time to allow interaction on the proposal.

-A total of eight formulations where chosen (eight nylon 6 / PP ratios) where each group would be responsible for two of the formulations. Each group was responsible for overseeing the processing for their formulations and performing the characterization.

\section{Student Responsibilities}

A strong emphasis was placed on student responsibility in the course. Barr and Tagg argue that the new paradigm for undergraduate education is one of shifting from teaching to learning 2 . Designing a course to achieve that is not trivial, it requires a shift in the fundamental relationship between the students and the course and how the course is structured. Unlike other courses where the professor defines the "A" by the choice of reading, homework, and tests, this course defines a "B," where the performance of the basic project requirements will only fulfill the basics. The students are asked to be responsible for their learning process by getting interested in any part of the project and to expand it beyond the basics. Within a group of students, the desired result is a project of multi-dimensional interests.

The goal was to aid the students in the transition from an academic to a workplace climate, where more than an individual's grade would be riding on the outcome of the project. It was pointed out that the companies involved, who had donated time on instruments, lecture time, etc. had effectively given money to the students and that they were expecting a certain level of professionalism from the students. The contributing companies were the customers for the course and should be treated as such. We attempted to treat the course project as a professional job rather than an academic assignment. As such it was emphasized that poor performance in the workplace could result in the loss of "employment" for the student.

In addition, the students were strongly encouraged to pursue aspects of the course which interest them in greater depth than was presented in class. This might include literature reviews on previous studies from a technical journal or additional characterization experiments on a particular set of samples which were giving ambiguous results, etc. 


\section{Faculty Responsibilities}

For faculty teaching course, the type of responsibility to the class and the students was different than in a typical lecture course. There were significantly more logistical issues which needed working out to complete the project in the time frame of a single semester. The lecture materials were presented in a format and style which emphasized on-demand learning and anchor teaching where advanced material is presented at a level which helps the students to understand the project and solve the problem at hand without becoming overly preoccupied with theory and academic exercise. In addition, since the students are strongly encouraged to pursue aspects of the material presented which interested them in greater depth, the faculty member(s) need to be available for after class discussion and maintain flexible office hours.

Since many of the topics covered during the semester in this course are normally taught either as full lecture courses or at the graduate level, the various lectures were presented to the students on a schedule to attempt to meet their needs for the background materials just prior to their need to use the information in the project.

The outline of the lecture topics for the course is given below:

I. Introduction to Polymers

Types of polymers, molecular weight distributions, crystallization, etc.

Blending of polymers

II. Polymer extrusion

Polymer flow behavior

Mixing of fluids and solids

Types of extruders-screw selection and design

Design of Experiment

III. Injection molding

Process design

IV. Polymer characterization

Mechanical properties

Morphology and mixing characterization

\section{Student Evaluation and Grading}

For grading purposes, a series of oral and written presentations were required at various stages during the semester. This culminated in a final formal presentation and written report which were presented in class with the industrial sponsors present. The presence of the industrial sponsors as the customers evaluating what they received for their investment of time and assistance increased the professionalism of the student reports.

Finally, a complete evaluation of the class performance was required of each student. This has proven successful in the freshman engineering design course at the University, where the students also work in groups for most of the semester. The students are asked to evaluate each member of the group by name as to their contribution to the group and the project. The students are also asked to evaluate their own performance to the project and group. 


\section{$\underline{\text { Summarv }}$}

This course has proven to be an success as implemented at the University of Maryland and it has gained a reputation as being a course which gives students a feel for what it will be like working as an engineer. The limitations of the course is that it requires fairly extensive preparation and developing contacts with local industry to provide the support and facilities to implement this style of course.

As a testament to the success of the course is that we have been able to place approximately $25 \%$ of the students taking the course with either part time or full time jobs in the local polymer industry as a direct result of their having taken this course.

\section{$\underline{\text { Acknowledgment }}$}

This work has been supported by the NSF TRP Award No.: DM19413092.

\section{Cited Literature}

1) D. Schon, "The New Scholarship Requires a New Epistemology: Knowing-in-Action," Change, November/December, 1995, p. 27-35.

2) R. Barr and J. Tagg, "From Teaching to Learning-A New Paradigm for Undergraduate Education," Change, November/December, 1995, p. 13-25.

\section{ROBERT M. BRIBER}

Robert Briber is an Assistant Professor of Materials and Nuclear Eng. at the Univ. of Maryland. He received his Ph.D. in Polymer Science and Eng. from the Univ. of Massachusetts in 1984. After graduating he worked as a staff scientist in the Polymers Division at NIST for seven years before joining the faculty at the Univ. of Maryland. His research interests include polymer blends, thermodynamics, morphological characterization and neutron scattering.

\section{DAVID I. BIGIO}

David Bigio is an Associate Professor of Mechanical Eng. at the Univ. of Maryland. He has been involved in the field of polymer processing for over 13 years. He received his Ph.D. from M.I.T. in 1986. Since joining the faculty of the Univ. of Maryland, he has established the Polymer Processing Laboratory which is engaged in research dedicated to the quantification of mixing as a basis for extruder performance evaluation.

\section{JAMES LOCHARY}

Jim Lochary received his Bachelor of Engineering Science in Chemical Engineering from Johns Hopkins University in 1983 and a Masters degree in Management from Johns Hopkins in 1993. He joined Adell Plastics, Inc. in 1983 and since 1993 he has been Manager of Process Engineering for the Baltimore facility. 